haemoglobin observed in all pregnant women (maximal at 18-22 weeks' gestation) ${ }^{13}$ results from an increase in $\mathrm{F}$ cells, each of which contains no more than $20 \%$ fetal haemoglobin. These $\mathrm{F}$ cells can be reliably detected only by sensitive fluorescence antibody techniques. With appropriate controls, these maternal $\mathrm{F}$ cells are unlikely to be confused microscopically with fetal cells, which have a content of over $80 \%$ fetal haemoglobin, stain deeply, and are refractile. In women with hereditary persistence of fetal haemoglobin, sickle cell anaemia, and homozygous $\beta$ thalassaemia for which they have not received transfusions, cells with a high fetal haemoglobin content may be mistaken for fetal red cells. But in Britain women with these disorders who become pregnant are relatively few, and they are likely to have been identified before delivery.

Flow cytometry and fluorescence activated cell sorting may be used to measure fetal cells in the maternal circulation, but these methods are not available in all laboratories. The Kleihauer test is simple and inexpensive and can be performed by any laboratory.

Duguid and Bromelow highlight a matter of even greater general concern regarding the reporting of results. None of the laboratories in their survey provided any clinical interpretation or recommendations regarding treatment as part of the laboratory report. For effective care, however, laboratories need to provide not only the results of tests but also interpretation and advice regarding treatment.

The Committee for Proprietary Medicinal Products provides only guidance, and each country in the European Union is free to implement its own policy. So, rather than following a recommendation of unproved benefit, it would be more appropriate to direct our efforts in Britain towards carefully identifying women requiring postnatal prophylaxis and introducing routine antenatal prophylaxis at least in the first at risk pregnancy.

Monoclonal anti-D immunoglobulin is now undergoing clinical trials and in a few years may be an unlimited, safe, and inexpensive therapeutic agent for immunoprophylaxis. If this happens then giving sufficiently large doses of antenatal and postnatal anti-D immunoglobulin may safely eliminate Kleihauer testing.

ELIZABETH A LETSKY

Queen Charlotte's Hospital,

London W6 0XG

Consultant perinatal haematologist

North London Blood Transfusion Centre,

London NW9 5BG

1 Mollison PL, Engelfriet CP, Contreras M. Blood transfusion in clinical medicine. 9th ed. Oxford:

Blackwell Scientific, 1993 .
Woodrow JC, Donohue WTA. Rh-immunisation by pregnancy: results of a survey and their relevance to prophylactic therapy. $B M \mathcal{F}^{1} 1968$;iv: 139 .

3 Poulain M, Huchet J. Appreciation de l'hemorragie foeta-maternelle apres l'accouchement en vue de la prevention de l'immunisation anti-D (bilan de 5,488 tests de Kleihauer). Revue Francaise de Transfusion 1971;14:219-24.

4 Medical Research Council Working Party. Report on the use of anti-D immunoglobulin for the prevention of isoimmunisation of Rh-negative women during pregnancy. Controlled trial of various anti-D dosages in suppression of $\mathrm{Rh}$ sensitisation following pregnancy. $B M^{f}$ 1974;ii:75-80.

5 Committee for Proprietary Medicinal Products, Commission of the European Communities Note for guidance: core summary of product characteristics for human anti-D immunoglobulin im. Note for guidance: core summary of product
Brussels: CEC,1994.(111/34463/92EN.)

6 Van Dijk B. Irregulair bloed groep antagonisme [Dissertation]. Leiden: Benda Nigmegen, University of Leiden, 1991.

7 Tovey LAD, Townley A, Stevension BJ, Taverner J. The Yorkshire antenatal anti-D immunoglobulin trial in primigravidae. Lancet 1983;ii:244-6.

8 Bowman JM, Chown JM, Lewis M, Pollock JM. Rh-isoimmunization during pregnancy: antenatal prophylaxis. Can Med Assoc F 1978;118:623-7.

9 American Association of Blood Banks. Standards for blood banks and transfusion services. 15th ed. Arlington, Virginia: AABB, 1993.

10 Bowman JM. The prevention of Rh immunization. Transfus Med Rev 1988;2:129-50.

11 Wagstaff W. Practical aspects of anti-D prophylaxis of haemolytic disease of the newborn. Association of Clinical Pathologists Broadsheet 1978;90:1-7.

12 Duguid JKM, Bronilow I. Value of Kleihauer testing after administration of anti-D immunoglobulin. BMF 1994;309:240.

13 Popat N, Wood WG, Weatherall DJ, Turnbull AC. Pattern of maternal F-cell production during pregnancy. Lancet 1977;ii:377-9.

\title{
The future of preventive dentistry
}

\author{
Fewer dentists, intervening less
}

The recent sharp fall in the prevalence of the two main dental diseases in industrialised countries calls for a radical revision of preventive dentistry. Dental disease is readily preventable without dentists: the falls have occurred for reasons external to dentistry, with dentists playing only an insignificant part. We need to reconsider what dentists should be doing. I shall use dental caries for illustration, but similar considerations apply to the other main dental disease, periodontal disease.

Dental caries has undergone a striking reduction in most industrialised countries over a relatively short period. In England and Wales in $1973,65 \%$ of 8 year old children had experienced caries; by 1993 this proportion had dropped to $17 \%$. In 15 year olds the mean number of decayed, missing, and filled teeth fell from 5.9 in 1983 to 2.5 in 1993.1 The proportion of $16-24$ year olds with 18 or more sound, untreated teeth increased from $44 \%$ in 1968 to $83 \%$ in $1988 .{ }^{2}$ The pattern of caries by tooth surface has also changed. Because two-surface caries is rare when the number of decayed, missing, and filled teeth is low, we are left with smaller lesions (mainly pit and fissure caries), fewer of which progress, and the progress is now much slower than before. ${ }^{3}$

These changes show that dental caries is preventable and can be dramatically reduced in a decade or so. What is more, prevention has been brought about by simple measures: fluoridated toothpastes and shifts in diet (caries being a disease induced by sugars) and, in the case of periodontal disease, improvements in oral cleanliness, partly through a fall in smoking.

No evidence exists that better treatment, preventive care, or increased dental manpower has contributed significantly to improvement. ${ }^{4}$ As Möller concluded in his review of oral health in Europe, increased spending "on traditional dental care has only a marginal effect on the population's oral health status."5

The fall in disease has led to an oversupply of dentists and the closure of dental schools. But the teaching and practice of prevention have remained virtually unchanged. The only notable response has been an attempt to identify "high risk" people and then apply traditional methods. This might be appropriate if one could predict who is at high risk, but such prediction is currently impossible. The individual-centred high risk strategy is popular with clinicians and with manufacturers of sugars and confectionery. It suggests that the problem rests solely with people at high risk. However, the distribution of both caries and sugar intake is continuous; as Rose has noted, "distributions commonly deny ownership of their tails!"6 Even if we were to find methods of prediction, there is a 
spectrum of disease. The cut off point defining high risk is arbitrary and relative.

In future, dentists should do fewer restorations, but of higher quality, and offer more appropriate prevention. A central tenet of modern preventive dentistry is to avoid intervening before prevention has been given a chance to work. With such slow progress in dental diseases the hallowed six monthly recall interval should be extended to 18 months or more. ${ }^{7}$ At the current low levels of dental caries and periodontal disease, traditional preventive methods such as fluoride rinsing, professionally applied fluorides, and intensive chairside dental health education are no longer cost effective. ${ }^{8}$ Dentists' preventive practice should be confined to supervising auxiliaries who apply fissure sealants to selected children and carry out simple preventive procedures ${ }^{9}$; such procedures, until now confined to children, have become more appropriate for older people, who are living longer and keeping their teeth longer.

The role of individual practitioners in prevention, however, is limited. Further reductions in dental disease require an integrated approach to common risk factors: dental diseases share common risks with heart disease, cancers, and accidents and so require a strategy directed at risk factors (such as diet, smoking, trauma, and stress) that affect a large proportion of the population. By making healthier choices the easier choices, such a strategy would enable people to increase control over, and improve, their health. Public health dentists should coordinate local health promotion initiatives. They and other health promoters should work with industry to improve key products (such as sugar free snacks and drinks). Other interventions require government action, as recognised in the Department of Health's Oral Health Strategy for England published last week. ${ }^{10}$ Fluoridating water supplies and developing policies on sugar production and promotion are among the most important strategies. If these measures were implemented in the next decade or two a visit to the dentist would be a rare event.

AUBREY SHEIHAM Professor

Department of Epidemiology and Public Health,

University College London School of Medicine,

London WCIE 6EA

1 OPCS Monitor. Dental caries among children in the United Kingdom in 1993. London: HMSO, 1994.

Todd JE, Lader D. Adult dental health 1988 United Kingdom. London: HMSO, 1991

3 Ekanayake LS, Sheiham A. Reducing rates of progression of dental caries in British schoo children. A study using bitewing radiographs. Br Dent $\mathcal{F}$ 1987;163:265-9.

4 Nadanovsky $P$. The relative contribution of dental services to changes in dental caries status of children in some industrialized countries since the 1970s [Dissertation]. London: University of London, 1993.

5 Möller IJ. Oral health in Europe. In: Leparski E, ed. The prevention of noncommunicable diseases: experiences and prospects. Copenhagen: WHO Regional Office for Europe, 1987:79-102.

6 Rose G. Environmental factors and disease: the man made environment. BMf 1987;294:963-

7 Sheiham A Is there a scientific basis for six-monthly dental examinations? Lancet 1977;ii:442

8 Foch CB. The costs, effects, and benefits of preventive dental care: a literature review. Santa Monica: Rand Corporation, 1981.(Report N-1732-RWJF.)

9 Nuffield Foundation. Education and training of personnel auxiliary to dentistry. London: The Nuffield Foundation, 1993.

10 Department of Health. An oral health strategy for England. London: Department of Health, 1994.

\title{
Some versions of joint commissioning
}

\author{
Truly seamless care will require structural and legislative changes
}

When the NHS reforms were first implemented in 1991 most emphasis was placed on developing the provider function. Many senior NHS managers opted for operational management, perceiving purchasing as at best uninteresting and at worst trivial and unnecessary. Three years later things look different. The minister of health, Dr Brian Mawhinney, boosted purchasing through a series of three speeches last year, ${ }^{1}$ and several organisations concerned with health service management now take purchasing seriously. ${ }^{2}$

In parallel, some far sighted managers and doctors saw the need to develop purchasing by encouraging collaboration between district health authorities and family health services authorities. These "commissioning agencies" began to offer a more coherent view of what commissioning might achieve by overcoming longstanding bureaucratic boundaries. Some of the first developments were in North West Thames and Wessex regions, where the benefits of joint commissioning were recognised early on, and some authorities, such as the Dorset Commissioning Agency, became a role model for others. ${ }^{34}$

Nevertheless, joint commissioning has developed slowly. Reasons for this include the continuing independent statutory basis of both district health authorities and family health services authorities and the substantial effort that running two authorities in parallel entails; the challenge of bringing together organisations at different stages of development; and the need to translate a commitment from top managers to those in more junior management positions as well as to general practitioners, particularly fundholders. ${ }^{5}$ In a recent paper commissioned by North West Thames Regional Health Authority Donald Light has addressed these difficulties in detail. ${ }^{6} \mathrm{He}$ considers locality based joint commissioning as "a movement to overcome the contradictions between needs-based purchasing by district health authorities and fundholding by larger GP practices." Until last year, the role of general practitioners in commissioning received scant attention except in places such as Hertfordshire that have large numbers of fundholders. With the support of nonfundholding general practitioners some agencies have set up different joint arrangements.

Light asserts that joint commissioning can overcome the fragmentation inherent in general practice fundholding. He suggests that it is "the most promising aspect of the NHS reforms because it allows an integrated way to commission services in order to maximise the health of everyone in a locality under a single coordinated budget and authority." $\mathrm{He}$ cites with approval Scotland and Northern Ireland, where health boards have traditionally managed the responsibilities of both district health authorities and family health services authorities. Unfortunately, it is not true to say that "joint commissioning has been practised for years in Scotland." Not only was genuine commissioning slower to develop in Scotland and Northern Ireland than in England but the evidence for collaboration is poor. Light also provides examples from other countries-notably the Netherlands, Sweden, the United States, and New Zealand-of how joint commissioning has developed in practice. His 